\title{
Implementing a Learning Collaborative Framework for States Working to Improve Outcomes for Vulnerable Populations: The Opioid Use Disorder, Maternal Outcomes, and Neonatal Abstinence Syndrome Initiative Learning Community
}

\author{
Charlan D. Kroelinger, $\mathrm{PhD},{ }^{1}$ Donna Addison, MPH, ${ }^{1,2}$ Mirelys Rodriguez, BA, ${ }^{1}$ Marion E. Rice, $\mathrm{MPH},{ }^{3}$ \\ Meghan T. Frey, MA, MPH, ${ }^{4}$ Hadley R. Hickner, MS, ${ }^{4}$ Mary Kate Weber, MPH, ${ }^{4}$ Trish Mueller, MPH, ${ }^{1}$ \\ Alisa Velonis, PhD, ${ }^{5}$ Keriann Uesugi, $\mathrm{PhD},{ }^{6}$ Lisa Romero, $\mathrm{DrPH},{ }^{1}$ Sanaa Akbarali, $\mathrm{MPH},{ }^{7}$ Natalie Foster, $\mathrm{MPH},{ }^{7}$ \\ Jean Y. Ko, PhD, ${ }^{1,2}$ Ellen Pliska, MHS, $\mathrm{CPH}^{7}{ }^{7}$ Christine Mackie, MPH, Shanna Cox, MSPH, \\ S. Nicole Fehrenbach, MPP, ${ }^{4}$ and Wanda D. Barfield, MD, MPH ${ }^{1,2}$
}

\begin{abstract}
The opioid crisis has impacted vulnerable populations, specifically pregnant and postpartum women, and infants prenatally exposed to substances, including infants with Neonatal Abstinence Syndrome. Lack of access to clinical and social services; potential stigma or discrimination; and lack of resources for provision of services, including screening and treatment, have impacted the health of these populations. In 2018, using a systems change approach, the Association of State and Territorial Health Officials (ASTHO) and the Centers for Disease Control and Prevention (CDC) convened an Opioid use disorder, Maternal outcomes, Neonatal abstinence syndrome Initiative Learning Community (OMNI LC) that included other federal agencies, national clinical and nonclinical organizations, and 12 state leadership groups. The purpose of the OMNI LC was to determine areas of focus and identify strategies and best practices for implementing systems change to improve maternal and infant outcomes associated with opioid use disorder (OUD) during the perinatal period. Activities included inperson convenings with policy goal action plan development, virtual learning sessions, intensive technical assistance (TA), and temporary field placements. The OMNI LC partnering agencies and state teams met bimonthly for the first year of the initiative. At the in-person convening, state teams identified barriers to developing and implementing systems change in activity-specific action plans within five areas of focus: financing and coverage; access to and coordination of quality services; provider training and awareness; ethical, legal, and social considerations; and data, monitoring, and evaluation. State teams also identified stakeholder partnerships as a necessary component of strategy development in all areas of focus. Four virtual learning sessions were conducted on the areas of focus identified by state teams, and ASTHO conducted three intensive TA opportunities, and five states were identified for temporary field placement. To successfully address the impact of the opioid crisis on pregnant and postpartum women and infants, states developed innovative strategies focused on increasing support, services, and resources. Moving forward, state teams will participate in two additional in-person meetings, continue to identify barriers to the work, refine and customize action plans, and set new goals, to effect broad-ranging systems change for these vulnerable populations.
\end{abstract}

\footnotetext{
${ }^{1}$ Division of Reproductive Health, National Center for Chronic Disease Prevention and Health Promotion, Centers for Disease Control and Prevention (CDC), Atlanta, Georgia.

${ }^{2}$ United States Public Health Service, Commissioned Corps, Atlanta, Georgia.

${ }^{3}$ CDC Foundation, Atlanta, Georgia.

${ }^{4}$ Division of Birth Defects and Infant Disorders, National Center on Birth Defects and Developmental Disabilities, Centers for Disease Control and Prevention (CDC), Atlanta, Georgia.

${ }^{5}$ Division of Community Health Sciences, University of Illinois at Chicago, Chicago, Illinois.

${ }^{6}$ Division of Epidemiology and Biostatistics, University of Illinois at Chicago, Chicago, Illinois.

${ }^{7}$ Association of State and Territorial Health Officials, Arlington, Virginia.
} 
Keywords: opioid crisis, opioid use disorder, opioid addiction, pregnancy, postpartum, neonatal abstinence syndrome, learning collaboratives

\section{Introduction}

O PIOID MISUSE IN the United States, including opioid misuse, opioid use disorder (OUD), and overdose among pregnant and postpartum women, is a public health crisis. $^{1-3}$ OUD is a problematic pattern of opioid use that causes significant impairment or distress. ${ }^{4}$ OUD at delivery hospitalization has increased, with the prevalence more than quadrupling in the last 15 years (1999-2014) from 1.5 per 1000 delivery hospitalizations to 6.5 per $1000 .^{2}$ In addition, from 2004 to 2014, the rate of US infants diagnosed with neonatal abstinence syndrome (NAS), often attributed to opioid withdrawal symptoms, increased $433 \%$, from 1.5 to 8.0 per 1000 hospital births. ${ }^{5}$

\section{OUD among pregnant women}

Preventing OUD before pregnancy with appropriate prescribing practices for opioid medications ${ }^{6}$ and the provision of well-woman or preconception care for recommended medical care and services may improve outcomes for women of reproductive age. ${ }^{7-9}$ Early identification of OUD during pregnancy is vital to improving outcomes for both mothers and infants. ${ }^{10}$ OUD during pregnancy is associated with adverse outcomes, including an increased risk for preterm labor, stillbirth, intrauterine growth restriction, and maternal death. ${ }^{11}$ Withdrawal from opioids is not recommended during pregnancy as it may result in preterm labor, fetal distress, or fetal demise. ${ }^{12}$ Medication-assisted treatment (MAT) with methadone or buprenorphine, in combination with behavioral therapy, is the standard of care for treatment for both pregnant and nonpregnant women ${ }^{12-15}$ and is associated with improved maternal and infant outcomes. ${ }^{6,16,17}$ As the prevalence of OUD among pregnant women has increased, many medical professionals who do not normally treat pregnant women with OUD may now provide care for these women, ${ }^{18}$ requiring increased provider awareness and education on standards of care and care coordination of medication management, behavioral or mental health care, or psychosocial support.

Pregnant women with OUD may avoid seeking prenatal care and other preventative health care services due to social stigma or discrimination, availability of services, fear of prosecution, or loss of infant custody. ${ }^{12,19-23}$ In addition, pregnant women with OUD may lack access to treatment programs or services that accommodate specific needs, including on-site child care. ${ }^{24}$ Women may concurrently use or misuse other substances, including prescribed medications (e.g., benzodiazepines, amphetamines, or other pharmacotherapies), alcohol, cocaine, cannabis, or tobacco, defined as polysubstance use, making diagnosis and treatment of OUD more complex. ${ }^{25}$

\section{OUD among postpartum women}

For postpartum women with OUD, there are multiple clinical and nonclinical care considerations, ${ }^{25}$ including treatment and care (e.g., postdelivery pain management, relapse prevention), ${ }^{26,27}$ diagnosis and treatment of concurrent conditions (e.g., postpartum depression, infectious disease), ${ }^{27}$ and other services (e.g., access to postpartum contraception, breastfeeding). ${ }^{28}$ To strengthen the mother-infant dyad relationship, postdelivery nonpharmacological care for the infant such as rooming-in (e.g., colocating the newborn and mother in the same room) encourages breastfeeding, infant bonding, and may increase the likelihood of an infant being released into the custody of the mother at hospital discharge. ${ }^{29}$

In addition to the stresses of being a new parent, postpartum women with OUD may encounter complicated psychosocial, environmental, or sociocultural barriers that limit care-seeking behavior and impact the ability to parent. ${ }^{21}$ In some states, laws require health care providers to report women with suspected or confirmed substance use during pregnancy, to child welfare services, resulting in the separation of the mother and infant. ${ }^{30,31}$ Parental substance use is associated with the separation of a child from the household. $^{32-34}$ While a variety of factors are associated with maternal substance use and loss of custody, ${ }^{35}$ maternal relapse is the primary concern in maintaining newborn custodial care and the mother-infant dyad, ${ }^{36}$ and risk of opioid overdose increases after delivery, with the highest rate of overdose occurring from 7 months to 1-year postpartum $(12.3 / 100,000$ person-days $){ }^{37}$

\section{Infants prenatally exposed to opioids, including infants diagnosed with NAS}

Prenatal exposure to opioids can lead to adverse infant outcomes, including NAS. ${ }^{38-40}$ NAS is often attributed to opioid withdrawal symptoms, but can occur from other drugs. Neonatal Opioid Withdrawal Syndrome (NOWS), a specific term to describe NAS due to opioid exposure, is an anticipated outcome for $40 \%-60 \%$ of infants who are born to mothers receiving MAT. ${ }^{12,41}$ Infants born with NAS are more likely to have longer hospital stays and more complications (e.g., respiratory distress syndrome, jaundice, and seizures) than infants without NAS diagnosis. ${ }^{5,42}$ Treatment protocols and practices for infants diagnosed with NAS, including use of screening and diagnostic tools, management of pharmacotherapy, and nonpharmacological support (e.g., minimizing environmental stimuli, responding early to an infant's symptoms), have varied among hospitals. ${ }^{4,44}$ Currently, there is no standardized clinical definition for NAS, although the Council of State and Territorial Epidemiologists has endorsed a position statement providing a proposed case definition for public health reporting. ${ }^{45}$ Some states have coordinated, statewide NAS surveillance activities, but NAS is not a reportable condition in all states. ${ }^{46,47}$ Clearly defining the signs of NAS may improve identification, linkages to care, clinical standards for the condition, and treatment. Consistent use of a definition will standardize surveillance, impacting coordination of care and intervention programs.

\section{Public health laws and policies}

Numerous policies and guidelines have been enacted, including those at the federal and state level to increase access to OUD prevention, treatment, and services; integrate OUD 
treatment into primary and prenatal care for pregnant women; improve identification and treatment of infants prenatally exposed to opioids; and expand state Medicaid coverage and payment policies. ${ }^{48}$ At the federal level, the Child Abuse Prevention and Treatment Act of 1974 (CAPTA) defined child abuse and neglect, and through multiple amendments, included additional information on identification of the federal role in funding prevention, assessment, and treatment activities for families. $^{49}$ The Protecting Our Infants Act of 2015 (POIA; Public Law 114-91) includes several mandates for the planning and coordination of federal activities related to prenatal opioid exposure and NAS, and the prevention, identification, and treatment of OUD in pregnant women. ${ }^{50}$ In addition, the Comprehensive Addiction and Recovery Act of 2016 (CARA) authorizes provision of related treatment services for NAS. ${ }^{51}$ Under CARA, infants diagnosed with NAS are authorized to have a "Plan of Safe Care" that addresses the health and substance use treatment needs of both the infant and the affected family or caregiver, modifying the original CAPTA legislation mandating plans of safe care for infants and postpartum women.

In 2018, the Family First Prevention Services Act enhanced support to children and families to prevent foster care placements by providing child welfare agencies with tools and resources to support families in crisis, in particular, families impacted by the opioid crisis. ${ }^{52}$ In addition, the Substance UseDisorder Prevention that Promotes Opioid Recovery and Treatment (SUPPORT) for Patients and Communities Act (H.R.6) was passed in 2018 and required Medicaid to cover MAT, including all U.S. Food and Drug Administrationapproved drugs, counseling services, and behavioral therapy for pregnant and nonpregnant women. ${ }^{53}$ SUPPORT also allows for state plan options to provide residential pediatric recovery center services to infants with NAS.

Many states have declared a state of emergency ${ }^{54-62}$ to allocate additional resources to reduce overdose deaths, enhance surveillance and reporting of nonfatal and fatal overdose deaths, mandate prescription drug monitoring programs, and garner federal support for resources, programs, treatment services, and prevention efforts. ${ }^{63}$ State capacity to implement systems identifying and connecting pregnant patients with OUD to treatment is often limited, ${ }^{64}$ with less than half of states prioritizing provision of services specifically for pregnant women. ${ }^{30}$ The implementation of systems change aimed at addressing OUD among pregnant and postpartum women and providing care for them and their infants supports care coordination among different clinical providers (e.g., obstetrician gynecologists, neonatologists, pediatricians, and family medicine specialists). ${ }^{9}$ As of February 1, 2019, 19 states have either established or funded drug treatment programs specifically targeting pregnant women, and 16 states and the District of Columbia, provide pregnant women with priority access to state-funded drug treatment programs, although barriers to services remain. ${ }^{30,65}$ Additional focus on accessible care, including interventions, programs or policies that address OUD during the postpartum period, ${ }^{48}$ and standardized implementation of Plans of Safe Care at the state level, increase accessible care among states and regions. ${ }^{21,66}$

\section{Public health practice}

To support state efforts to address OUD among pregnant and postpartum women and prenatal opioid exposure in infants, including infants diagnosed with NAS, Centers for Disease Control and Prevention (CDC)'s Division of Reproductive Health, in partnership with the National Center on Birth Defects and Developmental Disabilities, the Center for State, Tribal, Local, and Territorial Support, and the National Center for Injury Prevention and Control (NCIPC), collaborated with the Association of State and Territorial Health Officials (ASTHO) in establishing the Opioid use disorder, Maternal outcomes, and Neonatal abstinence syndrome Initiative Learning Community (OMNI LC). The purpose of the OMNI LC, a type of learning collaborative, is to disseminate strategies and best practices that support state programs and policies on OUD among these vulnerable populations. ${ }^{67}$

The Learning Community provides a framework or structure for states to develop actionable plans supporting program or policy systems change. CDC and other federal partners collaborate with ASTHO in implementing the OMNI LC by providing technical assistance (TA) such as up to date information on opioid surveillance and programmatic opportunities that can be leveraged for success. Statewide systems changes focused on these vulnerable populations can have broader equitable impact, resulting in improved outcomes for families affected by the opioid crisis.

\section{Using the Learning Collaborative Model as a Mechanism for Systems Change}

The OMNI LC was adapted from a previously implemented learning community model. ${ }^{68}$ From 2014 to 2018, CDC and ASTHO convened a type of learning collaborative-a multistate learning community - to support states in implementing a systems change approach to increase access to contraception, including immediate postpartum long-acting reversible contraception. $^{68,69}$ Participants of the learning community identified value in the intra- and interagency collaboration within states and among federal agencies and considered developed partnerships an important factor in implementation of strategies to build capacity for sustainable systems change. ${ }^{70-72}$ Participating state teams reported that the learning community itself supported strategy implementation by providing structure and accountability, thereby validating state-led efforts. ${ }^{73}$

The successes of the earlier learning community offer a model for states to address complex public health issues requiring coordinated response across many sectors, agencies, and partners, a strength of a collaborative learning model. ${ }^{69,71,74}$ The OMNI LC includes these components and requires multidisciplinary, multiagency state teams to participate in in-person meetings and virtual learning events ${ }^{68}$ to implement systems change activities targeting OUD among pregnant and postpartum women and prenatal opioid exposure in infants. ${ }^{67}$

To implement the OMNI LC, ASTHO partnered with a wide range of agencies and organizations, developed clear criteria for selecting states to participate in the activity, and identified core state team members critical for systems change. To provide states with timely and accurate national programmatic updates, ASTHO invited CDC, other federal agencies, and clinical and nonclinical membership organizations to participate in OMNI LC activities and engage in partner update meetings (Table 1). ASTHO identified the initial participating states for the OMNI LC by prioritizing states with a high prevalence or incidence of opioid-related behaviors and outcomes (e.g., NAS incidence, OUD prevalence, overdose 
Table 1. Federal Agencies, Clinical, and Nonclinical Membership Organizations Invited to Participate in the Opioid Use Disorder, Maternal Outcomes, and Neonatal Abstinence Syndrome Initiative Learning Community Kickoff Convening, 2018

Participant category

Federal agencies

Clinical membership organizations

Nonclinical membership organizations
Participant organization or agency

Administration for Children and Families

Centers for Disease Control and Prevention

Centers for Medicare and Medicaid Services

Center for Medicaid and Children's Health Insurance Program Services

Center for Medicare and Medicaid Innovation

Health Resources and Services Administration

Maternal and Child Health Bureau

Substance Abuse and Mental Health Services Administration

American Academy of Pediatrics

American College of Obstetricians and Gynecologists

Association of Maternal and Child Health Programs

American Public Health Services Association

National Association of County and City Health Officials

National Association of State Alcohol and Drug Abuse Directors

National Council of State Legislators death rates), available treatment for OUD (e.g., MAT for pregnant and postpartum women), a declared state of emergency, and developed interventions to broadly address the opioid crisis. To develop, adopt, and implement systems change, ASTHO encouraged state teams to include a core group of participants, including state health officials or commissioners, Medicaid Medical Directors, Title V Maternal and Child Health Directors, Mental Health, Behavioral Health or Alcohol and Drug Abuse Directors, and provider champions (i.e., champions are those with the knowledge, experience, and training to support applying evidence to practice). ${ }^{71}$
To conceptualize the complexity of issues experienced by women and their families with OUD or polysubstance use, including opioids, infants prenatally exposed to substances, and the impact on families, the Life Course Framework is incorporated into the OMNI LC (Fig. 1). The Life Course Framework conveys that health develops over a lifetime and across generations ${ }^{75}$ and provides useful context for state teams to consider the potential impact of policies on maternal and child health. Figure 1 displays the life course trajectories of pregnant and postpartum women with OUD or polysubstance use, partners, infants, and the family. For all,

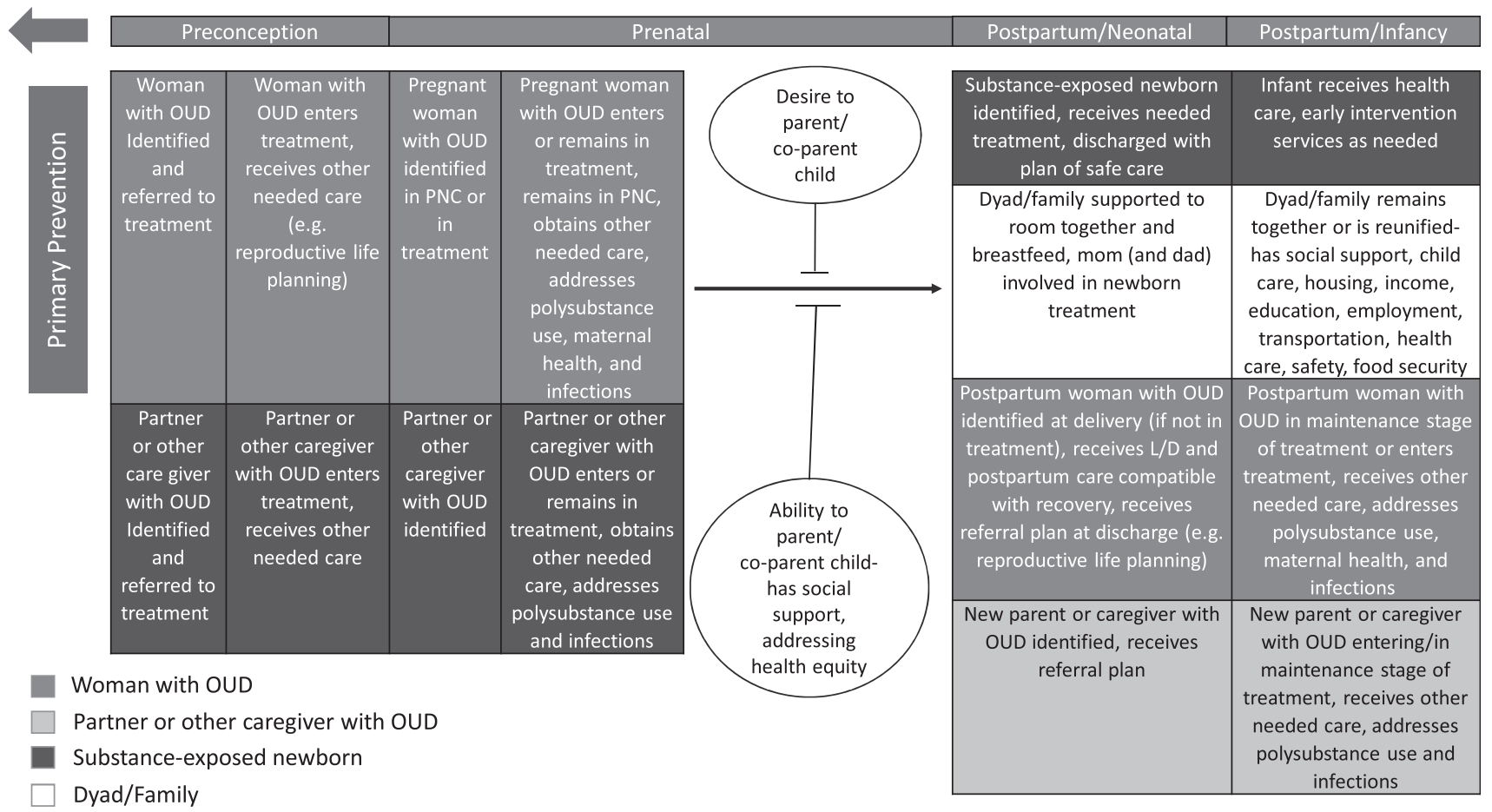

FIG. 1. Life course framework for pregnant and postpartum women with OUD and infants prenatally exposed to opioids, including infants with NAS: OMNI Learning Community, 2018. L/D, labor and delivery; NAS, neonatal abstinence syndrome; OMNI, Opioid use disorder, Maternal outcomes, and Neonatal abstinence syndrome Initiative; OUD, opioid use disorder. 
increased access to health care services, substance use treatment, and the development of Plans of Safe Care may aid in providing healthier, sustainable environments for the overall family unit. The Life Course Framework was used to identify opportunities for systems change by focusing on prevention and intervention opportunities for women and their infants.

To complement the life course trajectory, ASTHO, with technical input from CDC subject matter experts, developed a clear definition of policy and focus areas for systems improvement through the OMNI LC (Fig. 2). Policies are defined as documented statewide decisions or rules that are intended to (1) direct or influence the actions of targeted stakeholders or (2) influence systems development and organizational change. ${ }^{76,77}$ Policies may be legislative, regulatory, or organizational in focus, ranging from laws to protocols or guidelines. ${ }^{78}$ For the OMNI LC, the states' work was grouped into five areas of focus: financing, and coverage; access to and coordination of quality services; provider awareness and training; ethical, legal, and social considerations; and data, monitoring, and evaluation (Table 2). In addition, OMNI LC states identified stakeholder partnerships as essential to implement change in all areas of focus. Figure 2 links systems change in the areas of focus with the public health outcomes related to the prenatal, postpartum, and neonatal periods.

\section{OMNI Learning Community Activities}

The OMNI LC adapts activities of previous learning communities and incorporates new enhancement activities specific to the opioid crisis (Table 3). ${ }^{68,69}$ The OMNI LC includes in-person convenings, virtual learning sessions, peer-to-peer sharing, and TA to state teams. New enhancements complement existing standard activities, and include intensive TA provided by nationally recognized subject matter experts and community-based TA through an ASTHO field placement within a state or locality. The model for the OMNI LC (Fig. 3) posits that state-based programs and policies to address OUD among pregnant and postpartum women and prenatal opioid exposure in infants, including those with NAS, can leverage clinical policies and initiatives through a multistate collaborative. The activities occur within the context of the five areas of focus and the cross-cutting strategy of stakeholder partnership engagement. These combined activities inform the development and implementation of systems change at the state level.

To implement the OMNI LC, ASTHO uses a capacity building and technical assistance (CB/TA) model, which incorporates efforts that have been effective in addressing capacity needs of state and territorial health officials and agency staff, to strategically engage and support public health priorities. The CB/TA model implemented by ASTHO supports state health departments by requiring provision of oneon-one TA and training by national subject matter experts, connection of health departments to a national network of colleagues with similar goals, facilitation of virtual and inperson learning, and development of practices to strengthen health department infrastructure. The CB/TA model is an ASTHO 2018-2021 strategic priority, Improve Public Health Through Capacity Building, Technical Assistance, and Thought Leadership. ${ }^{79}$ ASTHO CB/TA includes the standard learning community activities, and new enhancements.

\section{Focus Area Framework}

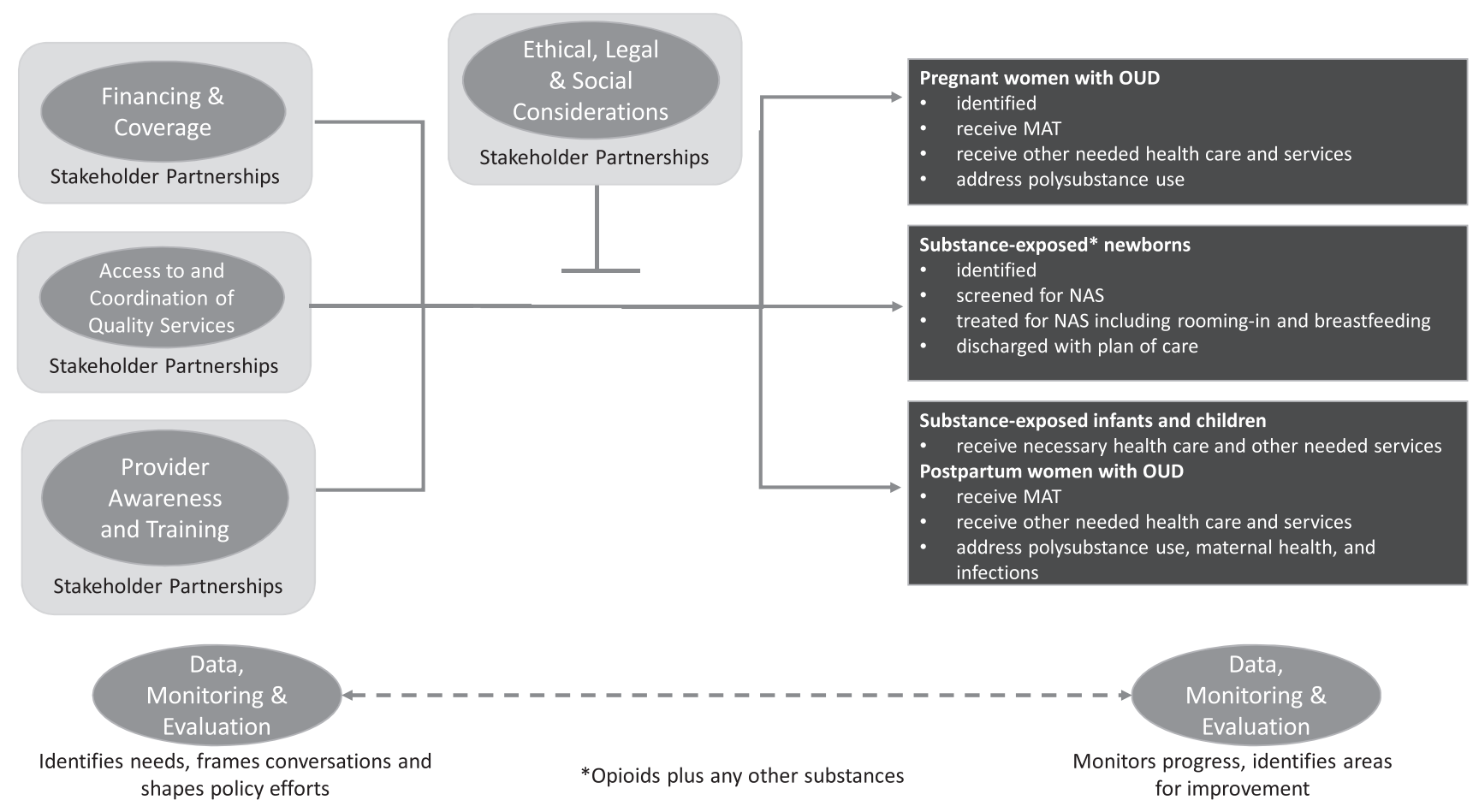

FIG. 2. Focus area and policy evaluation framework: OMNI Learning Community, 2018. MAT, medication-assisted treatment; NOWS, neonatal opioid withdrawal syndrome. *Opioids plus any other substances. 
Table 2. Areas of Focus: Opioid Use Disorder, Maternal Outcomes, and Neonatal Abstinence Syndrome Initiative LeARNing Community, 2018

\begin{tabular}{|c|c|c|}
\hline Focus area & Description & Example activities \\
\hline $\begin{array}{l}\text { Financing and } \\
\text { coverage }\end{array}$ & $\begin{array}{l}\text { Medical coverage, reimbursement } \\
\text { and billing strategies for } \\
\text { treatment of OUD during and } \\
\text { after pregnancy for prevention } \\
\text { efforts, and to sustain long-term } \\
\text { care provision }\end{array}$ & $\begin{array}{l}\text { Expand care coverage and improve linkages between programs } \\
\text { to use all available and appropriate reimbursement and } \\
\text { funding sources } \\
\text { Provide information and training for health care providers and } \\
\text { administrative staff on billing and coding procedures } \\
\text { Define use of current reimbursement codes and develop new } \\
\text { reimbursement codes or care bundles for ancillary or } \\
\text { additional services as needed }\end{array}$ \\
\hline $\begin{array}{l}\text { Access to and } \\
\text { coordination of } \\
\text { quality services }\end{array}$ & $\begin{array}{l}\text { Assessment of eligibility and } \\
\text { availability of services to aid in } \\
\text { treatment, referral, or recovery } \\
\text { efforts }(e . g ., \text { mental health } \\
\text { services, childcare, transportation } \\
\text { services), coordination of quality } \\
\text { care, and integration of ancillary } \\
\text { services }\end{array}$ & $\begin{array}{l}\text { Increase the number and type of providers across a state that } \\
\text { provide quality health and services to pregnant and postpartum } \\
\text { women with OUD and infants prenatally exposed to opioids } \\
\text { Develop provider networks in rural or remote areas, including } \\
\text { telehealth programs, that serve pregnant and postpartum } \\
\text { women with OUD and infants prenatally exposed to opioids } \\
\text { Gain an understanding of possible disparities to access quality } \\
\text { services across the state, including coverage constraints, types } \\
\text { of services offered }(e . g . \text {, availability of family-friendly } \\
\text { services and treatment), administrative barriers }(e . g . \text {., limited } \\
\text { office hours, location of services), and timeliness of care; then, } \\
\text { develop interventions to address disparities } \\
\text { Address gaps in coordination and management of care, including } \\
\text { coordination with other state-funded psychosocial services } \\
\text { (e.g., home visiting) and community-based services, } \\
\text { developing a referral system for services, or defining a } \\
\text { medical home }\end{array}$ \\
\hline $\begin{array}{l}\text { Provider awareness } \\
\text { and training }\end{array}$ & $\begin{array}{l}\text { Guidance, training, and education } \\
\text { for providers on treatment } \\
\text { protocols and guidelines to } \\
\text { standardize care, screen and refer } \\
\text { for treatment, and increase } \\
\text { familiarity with additional } \\
\text { clinical or social service } \\
\text { resources and relevant state- } \\
\text { specific laws and policies (e.g., } \\
\text { Plans of Safe Care) }\end{array}$ & $\begin{array}{l}\text { Increase awareness among and provide education to health care } \\
\text { providers on all of the following: } \\
\text { Risks and burden of OUD among pregnant and postpartum } \\
\text { women and NAS among infants prenatally exposed to opioids } \\
\text { Resources at the state, local, and community level for pregnant } \\
\text { and postpartum women with OUD and infants prenatally } \\
\text { exposed to opioids (e.g., MAT providers and OUD treatment } \\
\text { programs that serve pregnant and postpartum women, faith- } \\
\text { based organizations, peer counselors, home visiting, early } \\
\text { intervention, behavioral and mental health care) } \\
\text { Medically appropriate screening tools and treatment protocols to } \\
\text { standardize care across provider types (e.g., } \\
\text { obstetricians/gynecologists, maternal-fetal medicine } \\
\text { specialists, neonatologists, pediatricians, etc. }) \text { and ancillary } \\
\text { providers }(e . g ., \text { behavioral health specialists, drug treatment } \\
\text { specialists) } \\
\text { Systems for referral and care coordination, relevant laws or } \\
\text { regulations, and referral and/or reporting requirements as } \\
\text { required by CAPTA and CARA (e.g., Plans of Safe Care) } \\
\text { Unintentional bias or stigmatizing of pregnant and postpartum } \\
\text { women with OUD }\end{array}$ \\
\hline $\begin{array}{l}\text { Ethical, legal, and } \\
\text { social } \\
\text { considerations }\end{array}$ & $\begin{array}{l}\text { Programs, policies, or policy } \\
\text { amendments to address social } \\
\text { stigma and legal considerations } \\
\text { (e.g., mandatory reporting) that } \\
\text { impact uptake, access to, and } \\
\text { provision of clinical, substance } \\
\text { use, and availability of mental } \\
\text { health services }\end{array}$ & $\begin{array}{l}\text { Consider laws and regulations for mandatory reporting to child } \\
\text { welfare agency } \\
\text { Address fear of incarceration or custody loss that prevent } \\
\text { pregnant and postpartum women who use or misuse } \\
\text { substances from seeking clinical or social services } \\
\text { Reduce stigma experienced by pregnant and postpartum women } \\
\text { who use or misuse substances and their infants during care } \\
\text { Consider broader issues of justice and ethics toward vulnerable } \\
\text { populations }\end{array}$ \\
\hline $\begin{array}{l}\text { Data, monitoring, } \\
\text { and evaluation }\end{array}$ & $\begin{array}{l}\text { Monitoring the burden of substance } \\
\text { use or misuse through analysis of } \\
\text { surveillance data, evaluation of } \\
\text { programs, and policy or quality } \\
\text { improvement initiatives }\end{array}$ & $\begin{array}{l}\text { Collect and analyze data, or analyze existing programmatic and } \\
\text { service data to inform policy and programmatic change } \\
\text { Improve surveillance systems to monitor care quality indicators, } \\
\text { and conduct process and outcome evaluations }\end{array}$ \\
\hline
\end{tabular}

CAPTA, Child Abuse Prevention and Treatment Act; CARA, Comprehensive Addiction and Recovery Act; MAT, medication-assisted treatment; NAS, neonatal abstinence syndrome; OUD, opioid use disorder. 
Table 3. Capacity Building and Technical Assistance Activities: Opioid Use Disorder, Maternal Outcomes, and Neonatal Abstinence Syndrome Initiative Learning Community, 2018

Activity

In-person meetings

Virtual learning events/learning together from subject matter experts

Resource development/peer to peer sharing and collaboration

\section{ASTHOStat}

Community-based enhancement/ enhanced technical assistance
Activity description

State teams and federal and national partners convene for information sharing and to discuss state successes and challenges in developing policy for pregnant and postpartum women with substance use disorder and infants prenatally exposed to opioids, including those with NAS. State teams create action plans for policy development, adoption, and implementation for the subsequent year. Three inperson meetings will be held: a kick off meeting (November 2018), an expansion meeting (August 2019), and a closing meeting (August 2020).

State teams, federal and subject matter experts participate in virtual seminars for peerto-peer learning and contact with content experts. This includes:

ASTHOConnects-quarterly webinars focused on relevant topics, featuring subject matter experts or presentations from state teams.

ASTHOExperts-blogs, podcasts, and videos that provide a platform for thought leadership and expert opinion from a subject-matter expert on a state health priority and/or emerging topic.

State teams participate in developing resources to share with other states initiating similar activities. This includes ASTHOBriefs-short, to-the-point resources that provide a summary of a key topic, program, policy, or research finding of interest to health officials and agency staff.

A continuum of technical assistance designed to support health agencies with the development, implementation, and evaluation of a programmatic or performance area, including: on demand technical assistance and referrals, phone or email communication within a 24 hour period. Examples include peer-to-peer connections, quick compilation of existing resources, or referrals to federal agencies or national organizations.

Trend Analysis and Research: in-depth analysis and research on requested topics and resources. Examples include landscape analysis, policy scans, or profile data requests.

On-site technical assistance and expert consultation: on-site consultation from ASTHO, subject matter experts, and/or federal agency and national organization staff.

Local field-based support person placed in participating state or local health departments to enhance capacity and complement state team activities.

ASTHO, Association of State and Territorial Health Officials.
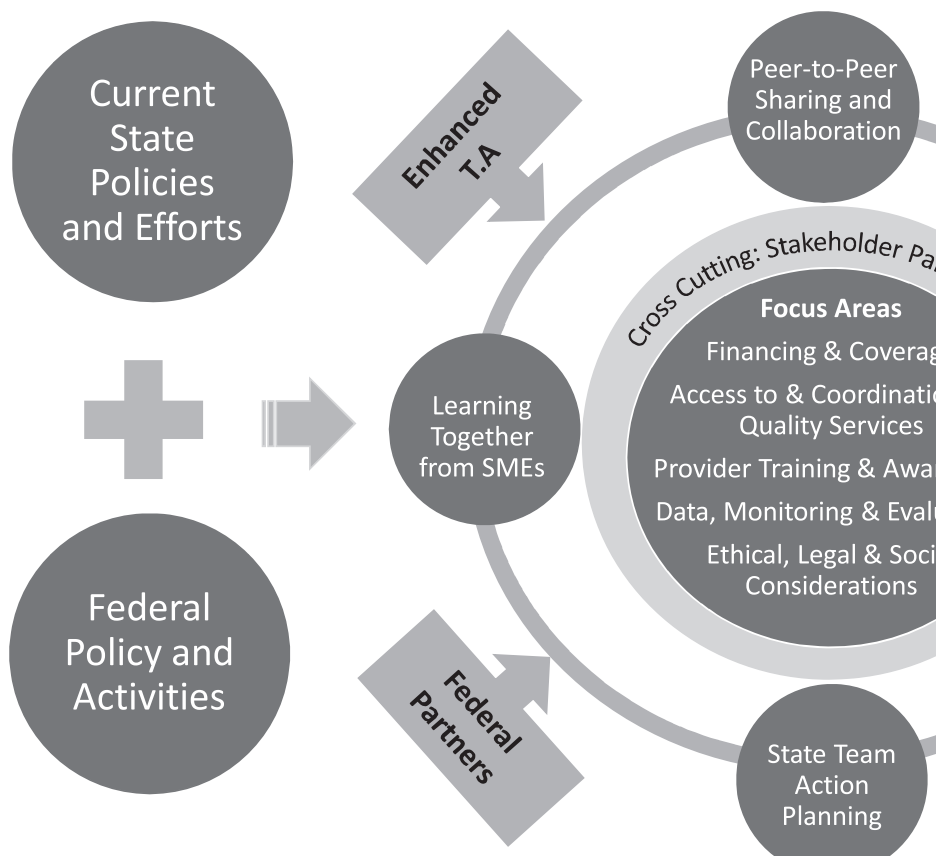

Financing \& Coverage

Access to \& Coordination of

Quality Services

Provider Training \& Awareness

Data, Monitoring \& Evaluation

Ethical, Legal \& Social

Considerations
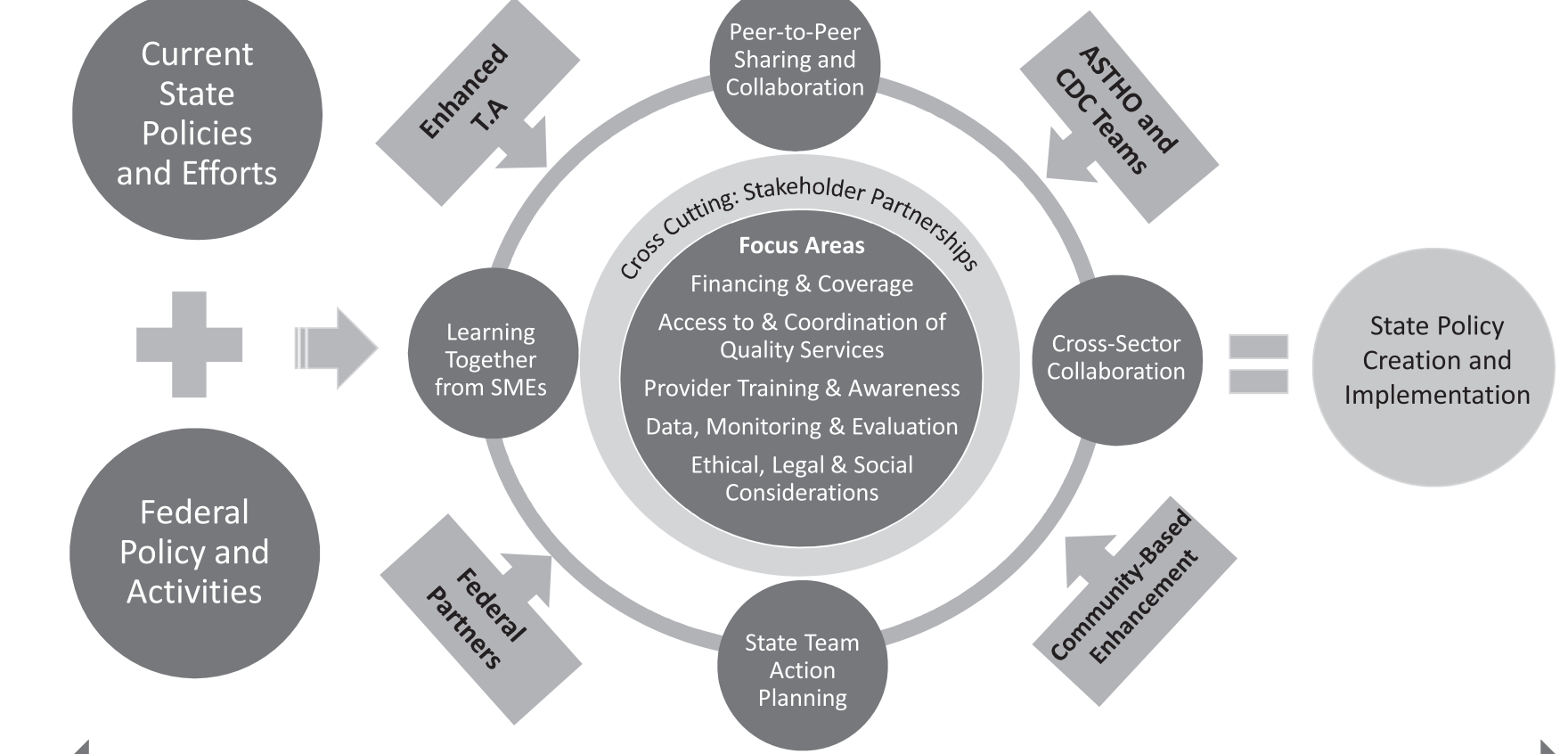

EVALUATION TEAM

FIG. 3. The OMNI Learning Community activities framework. Using evidence-based strategies, 2018. ASTHO, Association of State and Territorial Health Officials; CDC, Centers for Disease Control and Prevention; SME, subject matter expert; TA, technical assistance. 


\section{OMNI Learning Community Activities-Year 1}

In-person kickoff convening

On November 7-8, 2018, the OMNI LC was launched with a 2-day kickoff meeting in Arlington, Virginia. Cross-sector state teams representing Alaska, Florida, Illinois, Kentucky, Ohio, Nevada, Pennsylvania, Rhode Island, Vermont, Tennessee, Washington, and West Virginia participated. The convening featured panel presentations from federal and national partners, including clinical and nonclinical membership organizations, large group discussions by affinity group (e.g., all state health officials met for discussion, all provider champions met for discussion, and so on), team-building discussions aimed at encouraging collaboration among members of each team that had not previously met (e.g., some state health officials had not met behavioral or mental health directors), and state team action planning to guide activities for the subsequent year. Facilitators worked with teams to identify barriers and facilitators of systems change to address OUD among pregnant and postpartum women and prenatal opioid exposure in infants; analyze the root causes of these barriers; and determine state goals, strategies, and immediate action steps for developing, adopting, or implementing activities. State action plans were considered iterative documents, modified based on shifting jurisdictional priorities or staffing changes. Action plans served as both a marker of progress and an opportunity for states to request TA from ASTHO, CDC, and other federal agencies, or partner clinical and nonclinical organizations.

\section{Bimonthly virtual convening}

On a bimonthly basis, ASTHO hosted a virtual learning session entitled, "ASTHOConnects." These webinars focused on topics relevant to the OMNI LC and featured subject matter experts or presentations from state teams. In the first year of the OMNI LC, four webinars on the OMNI LC framework and other national initiatives, Plans of Safe Care, NAS, and the effects of unconscious bias or stigma encountered by women in the health care setting were presented to state teams, clinical membership organizations, federal agencies, and nonfederal organizations.

\section{Continuum of TA}

To support OMNI LC state teams, a continuum of TA, referred to as ASTHOStat, was offered by ASTHO, CDC, and other federal and national partners to support OMNI LC teams to develop and implement state action plans. ASTHOStat opportunities vary in intensity based on state requests and may include on-demand research provided by ASTHO such as policy assessment analyses or policy reviews, expert consultations, or in-depth, on-site TA. To date, three ASTHOStat TA opportunities have been provided: offering on-site support for state action plan development and presentation to other state leaders, facilitating peer-to-peer connections between state teams on medical care homes for infants with NAS, and compiling summary documents on public-facing opioid treatment maps.

\section{Local field placement}

To build state and local capacity to develop and implement activities outlined in state action plans, OMNI LC also in- cludes a component to place locally based public health professionals in health departments to provide additional programmatic support for up to 1 year. Health departments provide technical management and oversight of the field placement, and ASTHO provides guidance, input, and support for field placement activities with CDC technical input and subject matter expertise. The scope of work for a field placement varies by state, but is linked to the state action plan within areas of focus, including provider awareness and training and access to and coordination of quality services. Field placements provide additional support for stakeholder engagement. Field placements work to assure that local information and resources are disseminated to key target audiences, shared with the state and other local jurisdictions, and aligned with state action plans. These positions can enhance the collaboration between state and local health departments and inform opportunities for statemanaged practice change. Ongoing progress, challenges, and lessons learned from field placements are communicated regularly to ASTHO and CDC and shared with the larger OMNI LC.

In early 2019, a letter of invitation was sent to states in the OMNI LC for field placement applications. State teams submitted applications outlining a high-level work plan that describes activities to address critical areas of support and a justification for a field placement, along with letters of support from state and local health officials. Following an objective review process and site selection, ASTHO worked with the state teams to develop a scope of work and job description for the field placement with technical input from CDC. Five states were selected for placement, Florida, Kentucky, Nevada, Ohio, and Washington.

\section{Evaluating State Policies and Implementation of the OMNI LC Framework}

The evaluation of the OMNI LC, implemented by the University of Illinois at Chicago, identifies what can be feasibly accomplished at the state level in terms of systems change within a short timeframe. The evaluation is two-part. The outcome evaluation will assess (1) the extent to which state teams develop, adopt or implement state-level policies (i.e., short-term outcomes) to improve health outcomes for pregnant and postpartum women with OUD and their infants and (2) the defining characteristics of those systems changes (e.g., type of policy, targeted population), comparing policies during the time prior to states entering the OMNI LC to policies just before its closure (September 2018 through August 2020) in a pre/postdesign. The process evaluation will assess how state teams developed, adopted, or implemented policies in OMNI LC states and will examine the conditions under which states chose their policy goals and how and why states made progress toward achieving their policy goals.

Data sources for the evaluation include both qualitative and quantitative tools for measurement (Table 4). Three surveys will be administered over the course of the OMNI LC: a baseline assessment, a team collaboration assessment, and a postassessment. The baseline assessment examines states' current and future efforts to develop or implement systems change and other strategies to address OUD among 
Table 4. Evaluation Data Collection Timeline: Opioid Use Disorder, Maternal outcomes, and Neonatal Abstinence Syndrome Initiative Learning Community, 2018

\begin{tabular}{|c|c|c|c|c|c|c|}
\hline \multirow[b]{2}{*}{$\begin{array}{l}\text { Data collection } \\
\text { activity }\end{array}$} & \multirow[b]{2}{*}{ Description } & \multicolumn{5}{|c|}{ Timeline and cohort } \\
\hline & & $\begin{array}{l}\text { Baseline } \\
\text { cohort } 1 \\
\text { (October } \\
2018)\end{array}$ & $\begin{array}{c}\text { Midpoint } \\
\text { cohort } 1 \\
\text { (June to } \\
\text { July, 2019) }\end{array}$ & $\begin{array}{c}\text { Baseline } \\
\text { cohort } 2 \\
\text { (September } \\
\text { 2019) }\end{array}$ & $\begin{array}{c}\text { Midpoint } \\
\text { cohort } 2 \\
\text { (May to } \\
\text { June, 2020) }\end{array}$ & $\begin{array}{c}\text { Endpoint } \\
\text { cohorts } 1 \text { and } \\
2 \text { (June to } \\
\text { August 2020) }\end{array}$ \\
\hline $\begin{array}{l}\text { Readiness } \\
\text { assessment }\end{array}$ & $\begin{array}{l}\text { Type: Quantitative survey } \\
\text { Respondent: State team } \\
\text { Aim: Examine states' efforts to } \\
\text { develop or implement policies or } \\
\text { strategies to address OUD among } \\
\text { pregnant and postpartum women } \\
\text { and effects on their infants; gauge } \\
\text { the level of commitment among } \\
\text { stakeholders for potential policies }\end{array}$ & $X$ & & $\mathrm{X}$ & & \\
\hline $\begin{array}{r}\text { Collaboration } \\
\text { assessment }\end{array}$ & $\begin{array}{l}\text { Type: Quantitative survey } \\
\text { Respondent: Individual state team } \\
\text { members } \\
\text { Aim: Capture extent of prior } \\
\text { collaboration among organizations } \\
\text { within the state; capture dynamics } \\
\text { within state teams among team } \\
\text { members }\end{array}$ & $X$ & $X$ & $\mathrm{X}$ & & $X$ \\
\hline $\begin{array}{l}\text { Team } \\
\text { interviews }\end{array}$ & $\begin{array}{l}\text { Type: Telephone interview } \\
\text { Respondents: State team } \\
\text { Aim: Describe the experience teams } \\
\text { had during OMNI LC and in the } \\
\text { policy process; identify factors } \\
\text { impacting progress on state action } \\
\text { plan goals }\end{array}$ & & $\mathrm{X}$ & & $\mathrm{X}$ & \\
\hline Post assessment & $\begin{array}{l}\text { Type: Quantitative survey } \\
\text { Respondent: Individual state team } \\
\text { members } \\
\text { Aim: Capture perception of team } \\
\text { progress on activities and policy } \\
\text { goals }\end{array}$ & & & & & $\mathrm{X}$ \\
\hline $\begin{array}{l}\text { Systematic } \\
\text { review of } \\
\text { policy } \\
\text { documents }\end{array}$ & $\begin{array}{l}\text { Type: Systematic review } \\
\text { Source: Publicly available state } \\
\text { policy documents } \\
\text { Aim: Identify a fuller range of state } \\
\text { policy activities addressing OUD } \\
\text { among pregnant and postpartum } \\
\text { women and effects on their infants, } \\
\text { including NAS, proceeding or } \\
\text { concurrent with OMNI LC }\end{array}$ & $\mathrm{X}$ & $\mathrm{X}$ & $X$ & $\mathrm{X}$ & \\
\hline
\end{tabular}

OMNI LC, Opioid use disorder, Maternal outcomes, and Neonatal abstinence syndrome Initiative Learning Community.

pregnant and postpartum women and measures the level of commitment for systems change among stakeholders in each state. ${ }^{80}$ The team collaboration assessment is an individual team member survey, based on other validated instruments, that captures both the extent of prior collaboration among the organizations represented within the state teams and the dynamics of the team members themselves measured at multiple time points over the course of the OMNI LC. ${ }^{81-83}$ The postassessment focuses on individual team member perceptions of team progress on goals at the close of the OMNI LC. These quantitative data will be supplemented by up to two telephone interviews with state team members and will focus on the experience teams have had as part of the OMNI LC and on the identification of factors (e.g., barriers, facilitators, context) associated with making more or less progress on state action plan goals. ${ }^{78,84-89}$
During the first year of the OMNI LC, a descriptive systematic review of publicly available policy documents $(e . g$., protocols, plans, recommendations, guidelines, administrative rules, statutes, or laws) will be conducted to better understand the full range of activities addressing OUD among pregnant and postpartum women and infants prenatally exposed to substances, including those with NAS, within OMNI LC states. At the close of the OMNI LC, policy documents will be compared to determine any changes based on strategies implemented by the state teams.

\section{OMNI LC Next Steps}

Based on lessons learned from the initial year of the OMNI LC, ASTHO will refine the types of resources developed to 
support state teams and the TA provided upon request. In August 2019, the OMNI LC expanded, increasing the number of state teams to 15 states. For year 2, state teams were also required to engage with state-based Primary Care Associations and to ensure Federally Qualified Health Center and Community Health Center providers are a part of systems change, as these clinics provide services to a large segment of pregnant and postpartum women and infants. Each area of focus was reconfirmed and an additional focus area on consumer awareness identified by state teams during the inperson convening; during the second year of the OMNI LC, the new area of focus will be refined by ASTHO. Finally, a suite of published resources will be developed for all states to use. Publicly available ASTHOBriefs and ASTHOReports will provide essential information on effective policies and best practices for all state leaders focused on addressing the public health and clinical care of vulnerable populations.

Working together at all levels of leadership, states, federal agencies, and clinical and nonclinical organizations will partner to identify potential opportunities for improvements in financing and coverage of services, provider awareness and training, access to and coordination of quality care, ethical and equitable practices, and use of surveillance and monitoring data to support activities focused on pregnant and postpartum women with OUD and infants prenatally exposed to opioids. Such activities are anticipated to support systems change for screening, treatment, and recovery, impacting the health of families and saving lives, and improve the longterm health trajectories of vulnerable populations.

\section{Acknowledgment}

The authors acknowledge the support of the Opioid Response Coordinating Unit (ORCU) located within the NCIPC at the CDC.

\section{Disclaimer}

The findings and conclusions in this report are those of the authors and do not necessarily represent the official position of the Centers for Disease Control and Prevention.

\section{Author Disclosure Statement}

No other competing financial interests exist.

\section{Funding Information}

Partial funding of this activity was provided by CDC-RFAOT18-1802 and CDC-RFA-OT18-1804.

\section{References}

1. Gostin LO, Hodge JG, Jr., Noe SA. Reframing the opioid epidemic as a national emergency. JAMA 2017;318:1539-1540.

2. Haight SC, Ko JY, Tong VT, Bohm MK, Callaghan WM. Opioid use disorder documented at delivery hospitalizationUnited States, 1999-2014. MMWR Morb Mortal Wkly Rep 2018;67:845-849.

3. Lyden J, Binswanger IA. The United States opioid epidemic. Semin Perinatol 2019;43:123-131.

4. American Psychiatric Association: Diagnostic and statistical manual of mental disorders, 5th ed. Arlington, VA: American Psychiatric Publishing, 2013.
5. Winkelman TN, Villapiano N, Kozhimannil KB, Davis MM, Patrick SW. Incidence and costs of neonatal abstinence syndrome among infants with Medicaid: 2004-2014. Pediatrics 2018;141:e20173520.

6. Dowell D, Haegerich TM, Chou R. CDC guideline for prescribing opioids for chronic pain-United States, 2016. MMWR Morb Mortal Wkly Rep 2016;65:1-49.

7. Heil SH, Jones HE, Arria A, et al. Unintended pregnancy in opioid-abusing women. J Subst Abuse Treat 2011;40:199-202.

8. Schiff DM, Patrick SW. Treatment of opioid use disorder during pregnancy and cases of neonatal abstinence syndrome. JAMA Pediatr 2017;171:707.

9. Patrick SW, Schiff DM; Committee on Substance Use and Prevention. A public health response to opioid use in pregnancy. Pediatrics 2017;139:e20164070.

10. Goodman DJ, Wolff KB. Screening for substance abuse in women's health: A public health imperative. J Midwifery Womens Health 2013;58:278-287.

11. Maeda A, Bateman BT, Clancy CR, Creanga AA, Leffert LR. Opioid Abuse and dependence during pregnancy: Temporal trends and obstetrical outcomes. Anesthesiology 2014;121: $1158-1165$.

12. American College of Obstetricians Gynecologists. Opioid use and opioid use disorder in pregnancy. Committee Opinion No. 711. Obstet Gynecol 2017;130:e81-e94.

13. Mattick RP, Breen C, Kimber J, Davoli M. Methadone maintenance therapy versus no opioid replacement therapy for opioid dependence. Cochrane Database Syst Rev 2009; 3:CD002209.

14. Jones HE, Heil SH, Baewert A, et al. Buprenorphine treatment of opioid-dependent pregnant women: A comprehensive review. Addiction 2012;107:5-27.

15. Minozzi S, Amato L, Bellisario C, Ferri M, Davoli M. Maintenance agonist treatments for opiate-dependent pregnant women. Cochrane Database Syst Rev 2013;12:CD006318.

16. Ordean A, Kahan M, Graves L, Abrahams R, Kim T. Obstetrical and neonatal outcomes of methadone-maintained pregnant women: A Canadian multisite cohort study. J Obstet Gynaecol Can 2015;37:252-257.

17. Burns L, Mattick RP, Lim K, Wallace C. Methadone in pregnancy: Treatment retention and neonatal outcomes. Addiction 2007;102:264-270.

18. Hand DJ, Short VL, Abatemarco DJ. Treatments for opioid use disorder among pregnant and reproductive-aged women. Fertil Steril 2017;108:222-227.

19. Jackson A, Shannon L. Barriers to receiving substance abuse treatment among rural pregnant women in Kentucky. Matern Child Health J 2012;16:1762-1770.

20. Saia KA, Schiff D, Wachman EM, et al. Caring for pregnant women with opioid use disorder in the USA: Expanding and improving treatment. Curr Obstet Gynecol Rep 2016;5:257-263.

21. Substance Abuse and Mental Health Services Administration. A collaborative approach to the treatment of pregnant women with opioid use disorders. Rockville, MD: Substance Abuse and Mental Health Services Administration, 2016:1-124.

22. Angelotta C, Weiss CJ, Angelotta JW, Friedman RA. A moral or medical problem? The relationship between legal penalties and treatment practices for opioid use disorders in pregnant women. Womens Health Issues 2016;26:595-601.

23. Gressler LE, Shah S, Shaya FT. Association of criminal statutes for opioid use disorder with prevalence and treatment among pregnant women with commercial insurance in the United States. JAMA Netw Open 2019;2:e190338. 
24. Greenfield SF, Brooks AJ, Gordon SM, et al. Substance abuse treatment entry, retention, and outcome in women: A review of the literature. Drug Alcohol Depend 2007;86:1-21.

25. Substance Abuse and Mental Health Services Administration. Clinical guidance for treating pregnant and parenting women with opioid use disorder and their infants. Rockville, MD: Substance Abuse and Mental Health Services Administration, 2018:1-165.

26. Soens MA, He J, Bateman BT. Anesthesia considerations and post-operative pain management in pregnant women with chronic opioid use. Semin Perinatol 2019;43:149-161.

27. Gopman S. Prenatal and postpartum care of women with substance use disorders. Obstet Gynecol Clin North Am 2014;41:213-228.

28. Rosenthal EW, Baxter JK. Obstetric management of women with opioid use disorder. Semin Perinatol 2019;43:168-172.

29. Abrahams RR, MacKay-Dunn MH, Nevmerjitskaia V, MacRae GS, Payne SP, Hodgson ZG. An evaluation of rooming-in among substance-exposed newborns in British Columbia. J Obstet Gynaecol Can 2010;32:866-871.

30. Guttmacher Institute. Substance use during pregnancy, 2019. Available at: www.guttmacher.org/print/state-policy/explore/ substance-use-during-pregnancy Accessed July 9, 2019.

31. Ogunyemi D, Hernandez-Loera GE. The impact of antenatal cocaine use on maternal characteristics and neonatal outcomes. J Matern Fetal Neonatal Med 2004;15:253-259.

32. Meinhofer A, Angleró-Díaz Y. Trends in foster care entry among children removed from their homes because of parental drug use, 2000 to 2017. JAMA Pediatr 2019;173:881-883.

33. Patrick SW, Frank RG, McNeer E, Stein BD. Improving the child welfare system to respond to the needs of substanceexposed infants. Hosp Pediatr 2019;9:651-654.

34. Radel L, Baldwin M, Crouse G, Ghertner R, Waters A. Substance use, the opioid epidemic, and the child welfare system: Key findings from a mixed methods study. ASPE Research Brief. Washington, DC: U.S. Department of Health and Human Services, Office of the Assistant Secretary for Planning and Evaluation, 2018.

35. Canfield M, Radcliffe P, Marlow S, Boreham M, Gilchrist G. Maternal substance use and child protection: A rapid evidence assessment of factors associated with loss of child care. Child Abuse Negl 2017;70:11-27.

36. Jones HE, Terplan M, Meyer M. Medically assisted withdrawal (detoxification): Considering the mother-infant dyad. J Addict Med 2017;11:90-92.

37. Schiff DM, Nielsen T, Terplan M, et al. Fatal and nonfatal overdose among pregnant and postpartum women in Massachusetts. Obstet Gynecol 2018;132:466-474.

38. Finnegan LP, Connaughton JF, Jr., Kron RE, Emich JP. Neonatal Abstinence Syndrome: Assessment and Management. Addict Dis 1975;2:141-158.

39. Hudak ML, Tan RC; Committee on Drugs; Committee on Fetus and Newborn; American Academy of Pediatrics. Neonatal drug withdrawal. Pediatrics 2012;129:e540-e560.

40. Ko JY, Wolicki S, Barfield WD, et al. CDC grand rounds: Public health strategies to prevent neonatal abstinence syndrome. MMWR Morb Mortal Wkly Rep 2017;66:242-245.

41. Ecker J, Abuhamad A, Hill W, et al. Substance use disorders in pregnancy: clinical, ethical, and research imperatives of the opioid epidemic: A report of a joint workshop of the Society for Maternal-Fetal Medicine, American College of Obstetricians and Gynecologists, and American Society of Addiction Medicine. Am J Obstet Gynecol 2019; 221:B5-B28.
42. Patrick SW, Davis MM, Lehmann CU, Cooper WO. Increasing incidence and geographic distribution of neonatal abstinence syndrome: United States 2009 to 2012. J Perinatol 2015;35:650-655.

43. Bogen DL, Whalen BL, Kair LR, Vining M, King BA. Wide variation found in care of opioid-exposed newborns. Acad Pediatr 2017;17:374-380.

44. Association of State and Territorial Health Officials. Neonatal abstinence syndrome: How states can help advance the knowledge base for primary prevention and best practices of care. Arlington, VA: Association of State and Territorial Health Officials, 2014.

45. Council of State and Territorial Epidemiologists. Neonatal abstinence syndrome standardized case definition, 2019. Available at: https://cdn.ymaws.com/www.cste.org/resource/ resmgr/2019ps/final/19-MCH-01_NAS_final_7.31.19.pdf Accessed March 6, 2020.

46. Chiang KV, Okoroh EM, Kasehagen LJ, Garcia-Saavedra LF, Ko JY. Standardization of state definitions for neonatal abstinence syndrome surveillance and the opioid crisis. Am J Public Health 2019;109:1193-1197.

47. Jilani SM, Frey MT, Pepin D, et al. Evaluation of statemandated reporting of neonatal abstinence syndrome-Six states, 2013-2017. MMWR Morb Mortal Wkly Rep 2019; 68:6-10.

48. Saunders JB, Jarlenski MP, Levy R, Kozhimannil KB. Federal and state policy efforts to address maternal opioid misuse: gaps and challenges. Womens Health Issues 2018; 28:130-136.

49. U.S. Department of Health and Human Services. The child abuse prevention and treatment act, 2018. Available at: www .acf.hhs.gov/sites/default/files/cb/capta.pdf Accessed March 6, 2020 .

50. Congress.gov. Protecting Our Infants Act of 2015, 2015. Available at: www.congress.gov/bill/114th-congress/senatebill/799 Accessed March 6, 2020.

51. Congress.gov. Comprehensive Addiction and Recovery Act of 2016, 2016. Available at: www.congress.gov/bill/114thcongress/senate-bill/524/text Accessed March 6, 2020.

52. Children's Defense Fund. Family first prevention services act, 2018. Available at: www.childrensdefense.org/policy/ policy-priorities/child-welfare/family-first Accessed March 6, 2020 .

53. Congress.gov. The SUPPORT for patients and communities act (H.R.6), 2018. Available at: www.congress.gov/115/bills/ hr6/BILLS-115hr6enr.pdf Accessed March 6, 2020.

54. Walker B. Administrative Order No. 283. Alaska: Office of the Governor, ed. 2017. Available at: https://gov.alaska.gov/ admin-orders/administrative-order-no-283 Accessed March 6, 2020.

55. Ducey DA. Declaration of emergency and notification of enhanced surveillance advisory. Arizona: Office of the Governor, ed. 2017. Available at: https://azgovernor.gov/ sites/default/files/related-docs/opioid_declaration.pdf Accessed March 6, 2020.

56. Scott R. Executive Order Number 17-146. Florida: Office of the Governor, ed. 2017. Available at: www.flgov.com/ wp-content/uploads/2017/05/17146.pdf Accessed March 6, 2020.

57. Governor Patrick declares public health emergency, announces actions to address opioid addiction and treatment. Boston, MA, 2014. Available at: https://www.mass.gov/ doc/advisory-to-public-and-health-care-providers-on-opiateoverdose/download Accessed March 6, 2020. 
58. Hogan-Rutherford administration declares state of emergency, announces major funding to combat heroin and opioid crisis in Maryland. Maryland: Office of the Governor, 2017.

59. Brown K. Executive Order No. 18-01 Building Oregon's commitment to addiction prevention, treatment, and recovery priorities, and setting deadlines for statutory requirements, and declaring a public health crisis. Oregon: Office of the Governor, ed. 2018.

60. Wolf T. Proclamation of disaster emergency. Pennsylvania: Office of the Governor, ed. 2018. Available at: www.governor .pa.gov/newsroom/governor-wolf-declares-heroin-and-opioidepidemic-a-statewide-disaster-emergency Accessed March 6, 2020.

61. Governor issues executive orders creating "opioid emergency response team" \& five-day limit on initial opioid prescriptions for acute and post surgical usage. Columbia, SC, 2017. Available at: https://governor.sc.gov/news/201712/gov-henry-mcmaster-declares-public-health-emergencyopioid-epidemic Accessed March 6, 2020.

62. Levine MJ. Declaration of public health emergency. Virginia: Virginia Department of Health, ed., 2016. Available at: www.vdh.virginia.gov/commissioner/opioid-addiction-invirginia/declaration-of-public-health-emergency Accessed March 6, 2020.

63. Health Resources \& Services Administration. Opioid crisis, 2019. Available at: www.hrsa.gov/opioids?utm_campaign= enews05172018\&utm_medium=email\&utm_source=gov delivery Accessed June 19, 2019.

64. Jones CM, Campopiano M, Baldwin G, McCance-Katz E. National and state treatment need and capacity for opioid agonist medication-assisted treatment. Am J Public Health 2015; 105:e55-e63.

65. Patrick SW, Buntin MB, Martin PR, et al. Barriers to accessing treatment for pregnant women with opioid use disorder in Appalachian states. Subst Abus 2019;40:356-362.

66. Lloyd MH, Luczak S, Lew S. Planning for safe care or widening the net?: A Review and analysis of 51 states' CAPTA policies addressing substance-exposed infants. Child Youth Serv Rev 2019;99:343-354.

67. Kroelinger CD, Rice ME, Cox S, et al. State strategies to address opioid use disorder among pregnant and postpartum women and infants prenatally exposed to substances, including infants with neonatal abstinence syndrome. MMWR Morb Mortal Wkly Rep 2019;68:777-783.

68. Kroelinger CD, Waddell LF, Goodman DA, et al. Working with state health departments on emerging issues in maternal and child health: Immediate postpartum long-acting reversible contraceptives. J Womens Health 2015;24:693-701.

69. Association of State and Territorial Health Officials. Increasing access to contraception learning community, 2018. Available at: https://astho.org/maternal-and-child-health/ Increasing-Access-to-contraception/Learning-Community .close-out-Meeting-Summary-Report-Year-Four/ Accessed March 6, 2020.

70. DeSisto CL, Kroelinger CD, Estrich C, et al. Application of an implementation science framework to policies on immediate postpartum long-acting reversible contraception. Public Health Rep 2019;134:189-196.

71. Kroelinger CD, Morgan IA, DeSisto CL, et al. Stateidentified implementation strategies to increase uptake of immediate postpartum long-acting reversible contraception policies. J Womens Health 2019;28:346-356.

72. Rankin KM, Kroelinger CD, DeSisto CL, et al. Application of implementation science methodology to immediate postpartum long-acting reversible contraception policy rollout across states. J Matern Child Health 2016;20:173-179.

73. DeSisto CL, Estrich C, Kroelinger CD, et al. Using a multistate learning community as an implementation strategy for immediate postpartum long-acting reversible contraception. Implement Sci 2017;12:138.

74. Okoroh EM, Kane DJ, Gee RE, et al. Policy change is not enough: Engaging provider champions on immediate postpartum contraception. Am J Obstetet Gynecol 2018; 218:590.e1-590.e7.

75. Fine A, Kotelchuck M. Rethinking MCH: The life course model as an organizing framework. Rockville, MD: Health Resources and Services Administration, 2010.

76. Patrick SW, Faherty LJ, Dick AW, Scott TA, Dudley J, Stein BD. Association among county-level economic factors, clinician supply, metropolitan or rural location, and neonatal abstinence syndrome. JAMA 2019;321:385-393.

77. Teitelbaum JB, Wilensky SE. Essentials of health policy and law. Burlington, MA: Jones \& Bartlett Publishers, 2016.

78. Centers for Disease Control and Prevention. Overview of CDC's policy process. Atlanta, GA: Centers for Disease Control, US Department of Health and Human Services, 2012.

79. Association of State and Territorial Health Officials. ASTHO strategic plan: 2018-2021. Available at: https:// astho.org/About/2018-2021-ASTHO-Strategic-Plan/2018 Accessed March 6, 2020.

80. Shea CM, Jacobs SR, Esserman DA, Bruce K, Weiner BJ. Organizational readiness for implementing change: A psychometric assessment of a new measure. Implement Sci 2014;9.

81. Frey BB, H LJ, Lee SW, Tollefson N. Measuring collaboration among grant partners. Am J Eval 2006;27:383-392.

82. Marek LI, Brock D-JP, Jyoti S. Evaluating collaboration for effectiveness. Am J Eval 2015;36:67-85.

83. Greenwald HP, Zukoski AP. Assessing collaboration: Alternative measures and issues for evaluation. Am J Eval 2018;39:322-335.

84. Buse K, Mays N, Walt G. The health policy framework: Context, process and actors. In: Black N, Raine R, eds. Making health policy. New York: Open University Press, pp. 4-18, 2005.

85. Ingram $\mathrm{H}, \mathrm{Schneider} \mathrm{AL}$, de Leon $\mathrm{P}$. Social construction and policy design. In: Sabatier PA, ed. Theories of the policy process. Cambridge, MA: Westview Press, pp. 93-126, 2007.

86. Jones MD, McBeth MK. A narrative policy framework: Clear enough to be wrong. Policy Stud J 2010;38:329-353.

87. Sabatier PA, Weible CM. The advocacy coalition framework: Innovations and clarifications. Cambridge, MA: Westview Press, 2007.

88. True JL, Jones BD, Baumgartner FR. Institutional rational choice: An assessment of the institutional analysis and development framework. Cambridge, MA: Westview Press, 2007.

89. Zahariadis N. The multiple streams framework: Structure, limitations, prospects. Cambridge, MA: Westview Press, 2007.

Address correspondence to:

Charlan D. Kroelinger, PhD

Division of Reproductive Health

National Center for Chronic Disease Prevention and Health Promotion

Centers for Disease Control and Prevention (CDC) 4770 Buford Hwy, NE, MS F-74 Atlanta, GA 30341

E-mail: ckroelinger@cdc.gov 